\title{
Organistas e organeiros: influências mútuas entre Frei José Marques e Silva (1782-1837) e António Xavier Machado e Cerveira (1756-1828)
}

\author{
João Vaz \\ Escola Superior de Música de Lisboa, Instituto Politécnico de Lisboa, Portugal \\ Centro de Estudos de Sociologia e Estética Musical (FCSH - NOVA), Portugal
}

DOI: https://doi.org/10.31492/2184-2043.RILP2018.35/pp.21-31

\section{Resumo}

As relações profissionais entre compositores e fabricantes de instrumentos foram constantes ao longo da história da música e a ligação entre o tipo de órgão desenvolvido em Portugal (especialmente na região de Lisboa) durante o virar do século XVIII e um repertório específico produzido na mesma área e período já foi apontado. Frei José Marques e Silva (1782-1837) foi organista na Capela da Bemposta, onde António Xavier Machado e Cerveira (1765-1828) construiu um órgão em 1792. A escrita musical de Marques e Silva faz uso prolongado das idiossincrasias dos instrumentos de Cerveira e é altamente provável que o organista da Capela da Rainha e o organeiro régio se tivessem encontrado. A análise de várias obras de Marques e Silva sugere uma influência mútua: não apenas a música de Marques e Silva está claramente destinada aos órgãos de Cerveira, mas também algumas características específicas dos instrumentos parecem ter sido criadas a pedido do compositor.

Palavras-chave: órgão, registação, portugal, antigo regime, Marques e Silva, Machado e Cerveira.

\begin{abstract}
Professional relations between composers and instrument makers were a constant throughout music history and the connection between the type of organ developed in Portugal (especially in the region of Lisbon) during the turn of the 18th century and a specific repertoire produced in the same area and period has been already pointed out. Frei José Marques e Silva (1782-1837) was organist at the Bemposta Chapel, where António Xavier Machado e Cerveira (1765-1828) built an organ in 1792. The musical writing of Marques e Silva makes extended use of the idiosyncrasies of Cerveira's instruments and it is highly probable that the organist of the Queen's chapel and the Royal organ builder would have met. The analysis of several works by Marques e Silva suggests a mutual influence: not only is the music of Marques e Silva clearly intended for the the organs of Cerveira, but also some specific features of the instruments seem to have been created at the composer's request.
\end{abstract}

Keywords: organ, registration, portugal, ancien régime, Marques e Silva, Machado e Cerveira.

N.B. Escrito de acordo com as normas do Acordo Ortográfico de 1945, com as alterações do decreto-lei n. ${ }^{\circ}$ 32/73, de 6 de Fevereiro.

1. Este artigo é uma versão revista de uma comunicação apresentada no Encontro Nacional de Investigação em Música (Porto, Escola Superior de Educação / Escola Superior de Artes do Espectáculo, 8-10 de Novembro de 2018). 
As relações profissionais entre compositores e fabricantes de instrumentos são constantes ao longo da história da música, particularmente no campo da música de órgão. A morfologia dos instrumentos, tão variada através da Europa, dependendo do tempo e da região, ofereceu possibilidades - e criou limitações - aos compositores, tendo, portanto, um papel crucial na criação da sua música. No meu artigo «Dynamics and Orchestral Effects in late Eighteenth-Century Portuguese Organ Music: The Works of José Marques e Silva (1782-1837) and the Organs of António Xavier Machado e Cerveira (1756-1828)» (Vaz, 2013), abordei já este assunto, no contexto da relação entre a música de órgão produzida em Portugal no final do século XVIII e as primeiras décadas do século XIX - principalmente em Lisboa e nas áreas circundantes - e o tipo de instrumento desenvolvido nessa região no mesmo período.

No caso de Portugal, a documentação sobre os órgãos em que os compositores executavam suas obras não é abundante. Na mais antiga fonte ibérica de música de tecla, a Arte nouamente inventada pera aprender a tanger de Gonçalo de Baena (Baena, 1540), impressa em Lisboa, o órgão representado na folha de rosto e as letras da tablatura (pensadas para ser recortadas e coladas nas teclas) dão uma indicação clara de que as peças foram compostas tendo em vista um teclado com a extensão de Dó1, Ré1, Mi1, Fá1, Sol1, Lá1 - Sol4 (Baena, 1540, p. [viii]) $)^{2}$. Uma fonte posterior, o Livro de obras de Órgão Juntas pela coriosidade de P. P. Roque da Cõceição ${ }^{3}$, um manuscrito com obras de vários autores, compilado em 1695, exibe o diagrama de um teclado também com «oitava curta», mas atingindo o Lá. A presença de várias obras do tipo «meio registo $»^{4}$ indica a presença de um registo solístico de tiple (como a Corneta real) e algumas indicações ao longo das peças sugerem a presença de palhetas. Estas são, evidentemente, indicações muito gerais, das quais não é possível inferir nenhum tipo de interacção directa entre organistas e construtores. No entanto, no final do século XVIII, quando a organaria e a música para órgão se moviam numa nova direcção claramente distanciada da tradição ibérica, os

2. «Estas son las letras que han de ser puestas en las teclas assi como en el organo pintado parece. Pueden las cortar daqui y apegarlas encima de las teclas; de modo que los dedos no las toquen» (Estas são as letras que devem ser postas nas teclas como no órgão pintado [na folha de rosto] aparece. Podem ser cortadas daqui e coladas nas teclas de forma que os dedos não as cubram).

3. P-Pm MM 43.

4. A expressão «meio registo» designa um género associado ao chamado «teclado partido» - uma característica comum à maioria dos órgãos peninsulares do século XVII. Nesses instrumentos, o teclado era dividido entre o Dó e o Dó sustenido centrais, correspondendo a cada uma das metades um conjunto de registos independente. Assim, era possível fazer coexistir num só teclado uma melodia com um timbre brilhante e um acompanhamento com uma registação mais discreta. 
sinais de relação entre música e instrumentos (e entre organistas e organeiros) tornam-se mais evidentes ${ }^{5}$. Neste contexto, as figuras do organista e compositor Frei José Marques e Silva e do organeiro António Xavier Machado e Cerveira, quase contemporâneos e com uma vasta produção nos domínios correspondentes, assume especial relevo.

Frei José Marques e Silva nasceu em 1782 em Vila Viçosa, onde teve a sua primeira formação musical, e entrou no Convento dos Paulistas em Lisboa por volta de 1800. Nesse mesmo ano, foi admitido na Irmandade de Santa Cecília (na qual a afiliação era obrigatória para todos os músicos activos em Lisboa). Em 1806, foi nomeado organista na Capela da Bemposta (no Palácio da Rainha), onde se tornou mestre de capela em 1816. Em 1821, após um longo processo envolvendo uma competição com António José Soares, assumiu o posto de mestre no Seminário Patriarcal em Lisboa, a escola de música mais importante da época. Composta principalmente para a Igreja, a sua produção é impressionante, incluindo várias obras para órgão solo e cerca de uma centena de obras vocais, a maioria dos quais com acompanhamento de órgão obbligato (Vaz, 2010, Vol. 2, pp. 211-273) ${ }^{6}$.

A música para órgão de Frei José Marques e Silva, tanto nas peças a solo como nas obras vocais com órgão, é claramente destinada aos instrumentos portugueses da época, nomeadamente os de António Xavier Machado e Cerveira, que construiu mais de uma centena de órgãos, incluindo o da Capela da Bemposta. Uma das características mais marcantes dos órgãos de Machado e Cerveira é a presença do anulador de cheios. Este dispositivo consiste numa corrediça deslizante (activada por meio de um pedal) colocada entre o someiro principal e um someiro secundário que contém a tubaria dos registos das misturas e as suas respectivas corrediças. O organista podia facilmente cortar o fornecimento de vento para o someiro dos cheios, mudando rapidamente entre forte e piano (ou entre o Cheio e o Flautado) num órgão com um único teclado. Essas mudanças de dinâmica tornaram-se tão populares na música de órgão da época, que o anulador de cheios pode ser encontrado até em instrumentos muito pequenos. Em instrumentos maiores, os registos das palhetas horizontais também eram separados do someiro principal por corrediça deslizante operada por um segundo pedal (Vaz, 2013, pp. 159-162).

5. Sobre a história da organaria em Portugal, nomeadamente a relação com a escola de Echevarría no século XVII e as transformações derivadas da influência italiana a partir do século XVIII, ver por exemplo as teses de doutoramento de Marco Brescia, L'école Echevarría en Galice et son rayonnement au Portugal (Brescia, 2013) e de João Vaz, A obra para órgão de Fr. José Marques e Silva (1782-1837) e o fim da tradição organística portuguesa do Antigo Regime (Vaz, 2010).

6. Esta secção da tese contém um catálogo das obras com órgão. Os capítulos 3 e 4 (vol. 1, pp 81-119 e 120-146) incluem respectivamente uma análise detalhada das obras para órgão solo e uma análise geral das obras vocais com órgão. 
Praticamente toda a música de José Marques e Silva exige o uso deste dispositivo. No seu primeiro autógrafo datado - o Benedictus Dominus Deus Israel para coro SATB e baixo contínuo (1806) - a linha do baixo cifrado segue a dinâmica das vozes. Esta obra foi escrita para a Basílica de Mártires, em Lisboa, onde o órgão (construído em 1785 por Machado e Cerveira) possui um anulador de cheios e pode facilmente realizar aquelas mudanças de dinâmica.

Outra característica dos órgãos de Machado e Cerveira é a presença de registos de palheta de ressonador curto, na maioria dos casos concebidos como registos solísticos. Indicações para o uso de registos de palheta como o Fagote, a Clarineta ou o Oboé (típico dos órgãos de Cerveira) podem ser encontradas em toda a música de órgão de Frei José Marques e Silva, especialmente nas suas obras a solo.

Embora interessantes, estas relações entre a música e os instrumentos não implicam necessariamente uma influência directa entre o compositor e o organeiro. É razoável supor que Machado e Cerveira se teria cruzado com Marques e Silva ao visitar o órgão da Bemposta, mas não há prova documental dessa ligação.

Os seis órgãos da Basilica de Mafra foram construídos entre 1793 e 1807 por Joaquim António Peres Fontanes e António Xavier Machado e Cerveira. Os últimos dois a serem concluídos - os órgãos do Evangelho e da Epístola, na Capela-Mor - foram inaugurados a 4 de Outubro de 1807, tendo um substancial número de composições envolvendo os seis órgãos sido produzida durante esse ano. Pouco depois disso, as Invasões Francesas e o consequente exílio da corte portuguesa no Brasil levaram a uma certa deterioração no uso dos instrumentos. Uma década depois - possivelmente em conexão com o fim das guerras napoleónicas e a perspectiva do regresso da família real - os seis órgãos foram submetidos a uma intervenção profunda. A intenção destes trabalhos, realizados apenas por António Xavier Machado e Cerveira (Fontanes morre em 1818), não era apenas reparar os instrumentos, mas também aumentá-los ${ }^{7}$.

A produção musical para Basílica de Mafra por volta de 1807 (destinada aos seis órgãos), é dominada por compositores do virar do século, como António Leal Moreira (1758-1819), João José Baldi (1770-1816) e Marcos Portugal (17621830). Baldi e Leal Moreira morreram logo após as Guerras Napoleónicas e Marcos Portugal, que na época era a figura musical dominante em Lisboa, juntou-se à Família Real no Brasil em 1810, aí permanecendo até à sua morte. Foi exatamente nesta segunda década do século XIX que a reforma dos órgãos de Mafra

7. Sobre a história da construção dos seis órgãos actualmente existentes na Basílica do Palácio Nacional de Mafra, ver João Vaz, The Six Organs in the Basilica of Mafra: History, Restoration and Repertoire (Vaz, 2015, pp. 83-101) e Gerhard Doderer, Beiträge zur Orgelbaugeschichte von Mafra (Portugal), (Doderer, 2005, pp. 81$110)$. 
começou - o mesmo período em que José Marques e Silva estabelecia a sua reputação como compositor.

Os trabalhos realizados na Basílica de Mafra por Machado e Cerveira após as Guerras Napoleónicas envolveram todos os seis instrumentos. Todos os órgãos foram desmontados, reparados e mais ou menos transformados. A evolução dessas obras teve reflexos na produção musical para Mafra. Após 1807 (quando foram produzidas várias obras para os seis órgãos), há uma falta de actividade que coincide com as Invasões Francesas. A actividade composicional foi retomada por volta de 1812, envolvendo gradualmente dois, três, quatro e cinco órgãos. Infelizmente, os trabalhos foram interrompidos na década de 1820 (Machado e Cerveira morreu em 1828) e várias tarefas, como a remontagem do órgão de São Pedro d'Alcântara, permaneceram inacabadas até ao recente restauro de todo o conjunto, concluído em 2010 (Vaz, 2015, pp. 88-89) ${ }^{8}$.

Figura 1. Basílica de Mafra, Capela-Mor.

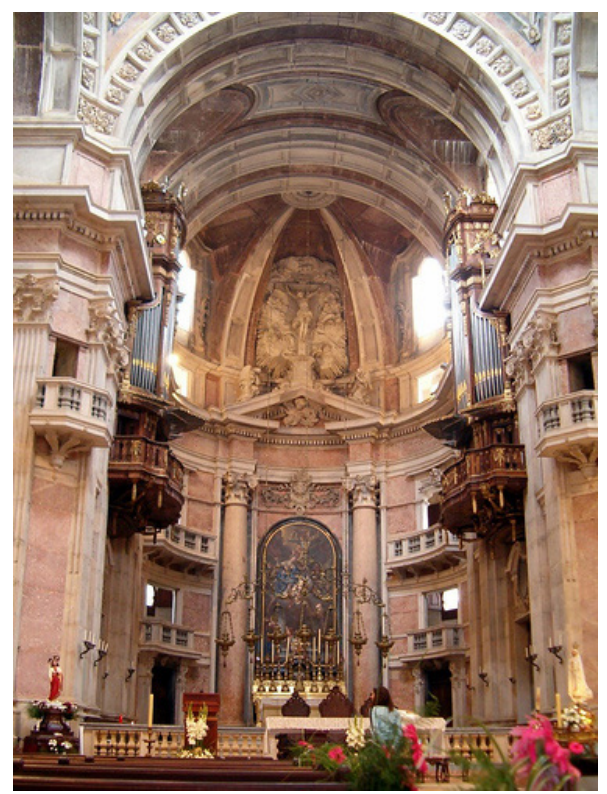

Aparentemente, Machado e Cerveira deu atenção especial aos dois órgãos da Capela-Mor (Figura 1). Estes instrumentos eram originalmente muito menores do que hoje, porque a existência de uma parede de pedra por detrás das tribunas não permitia um someiro suficientemente profundo. Cerveira tentou resolver esse problema colocando o someiro secundário (someiro de cheios) dois metros acima do someiro principal. Embora essa solução fosse - e ainda seja - menos favorável 
para o vento, permitiu que os órgãos fossem consideravelmente ampliados (Vaz, 2015, pp. 87-88). Sobre as especificações originais (de 1807) dos órgãos da Capela-Mor não subsiste qualquer documentação. No entanto, é óbvio que o órgão da Epístola (originalmente construído por Joaquim António Peres Fontanes) foi alterado para se adequar ao conceito de Machado e Cerveira. Ambos os órgãos passaram a ter pedais de anulação para os registos do cheio e das palhetas horizontais (geralmente, os instrumentos de Fontanes têm esse sistema apenas para o cheio). Os pedais anuladores no órgão do Evangelho, no entanto, diferem da prática usual de Cerveira. Enquanto que o anulador dos cheios tem uma aparência normal (um pedal deslizante), o anulador das palhetas apresenta uma configuração sem paralelo na factura de Cerveira (Fig. 2).

Figura 2. Basílica de Mafra, órgão do Evangelho | Pormenor dos pedais de anulação de cheios (esquerda) e de palhetas (direita).

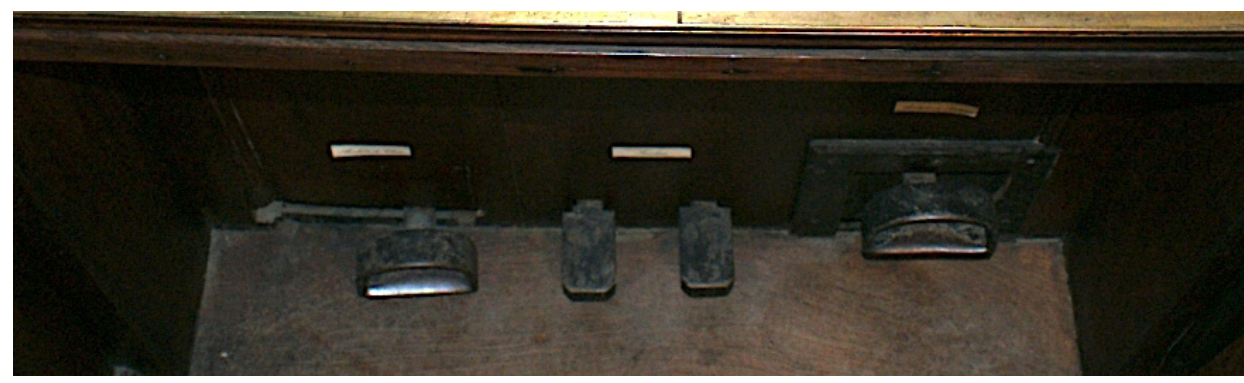

Este pedal tem quatro posições diferentes, permitindo que o executante alterne entre as palhetas suaves de ressonador curto e a trombetaria horizontal, ou use ambas (ou nenhumas), sem levantar as mãos do teclado.

Figura 3. Esquema de funcionamento dos pedais de anulação de cheios e de palhetas no órgão do Evangelho (Basílica de Mafra).

Trompa de Batalha (m.e.), Clarim (m.d.), Fagote (1.h.), Oboe (r.h.) activos

Trompa de Batalha (m.e.),

Clarim (m.d.) activos
Fagote (m.e.), Oboe (m.d.) activos

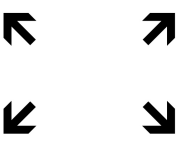

todas as palhetas inactivas 
Parece altamente provável que a instalação deste sistema, situação única nos órgãos de Machado e Cerveira, tenha sido sugerida por um organista. Também é provável que Frei José Marques e Silva - dada sua posição no Palácio da Bemposta $^{9}$ e no panorama da música sacra portuguesa da época - tivesse sido a escolha óbvia como consultor de Cerveira. Embora não haja provas desta relação, o facto é que uma das primeiras obras que se sabe terem sido escritas para Mafra após a vitória sobre as tropas francesas foi um Te Deum para coro masculino e dois órgãos de Frei José Marques e Silva, datado de $1812^{10}$. Nesta obra, a parte do Orgão $1^{\circ}$ exige mudanças rápidas de registação, apenas possibilitadas pelo uso dos dispositivos existentes no órgão do Evangelho ${ }^{11}$. Uma secção (cc. 16-33) do primeiro andamento (Te Deum laudamus) exige uma mudança de Flautado para Clarim, e novamente para Flautado, Clarim, Cheio, Flautado, Obué ${ }^{2}$ e Flautado, no decorrer de apenas quinze compassos (ver Figuras 4a e 4b).

Figura 4a. Frei José Marques e Silva, Te Deum (P-Mp R Mms 13/2, f. 3v.).

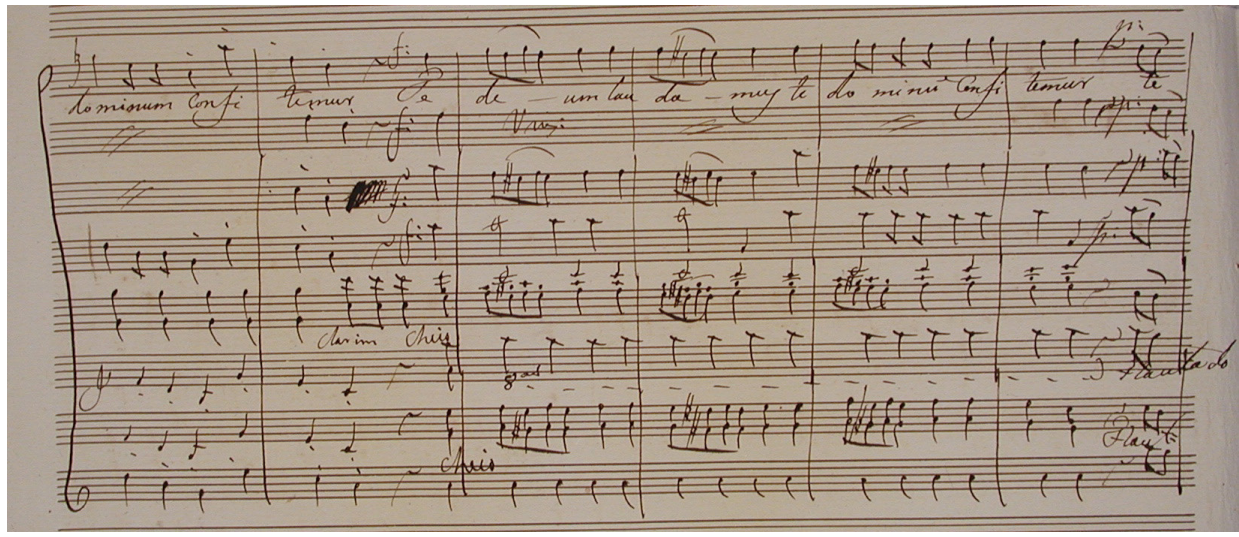

9. A Capela da Rainha (Bemposta), juntamente com a Capela Real e a Igreja Patriarcal, eram, na época, as posições de topo para organistas em Lisboa

10. P-Mp R Mms 13/2. Autógrafo que ostenta a inscrição "Hymno / Tedeum Laudamus / Concertado de 3 Cantores, coro, e dois Orgãos Obrigados. / Feito P.a a Real Bazilica de Mafra. / Original de Fr. Joze Marques e S.a / em Lx.a Anno de 1812".

11. A análise de outras obras de Frei José Marques e Silva escritas para a Basílica de Mafra (P-Ln FCR 198//26) indica que o papel liderante era sempre dado aos órgãos da Capela-Mor e que o coro estava aí colocado (Vaz, "The Six Organs in the Basilica of Mafra", 89-96 e Kate Pearson, Three Organ Quartets by António José Soares: A Study in Part Distribution for the Organs in the Basilica of Mafra, Portugal (Relatório de Projecto Artístico de Mestrado, Escola Superior de Música de Lisboa, 2012).

12. O termo «Obué» é usado neste texto com esta grafia (a usada por Marques e Silva) quando se refere às indicações autógrafas. A grafia actual («Oboé») é usada para indicar o registo com este nome existente na órgão do Evangelho na Basílica de Mafra (nomenclatura proposta durante o restauro de Dinarte Machado em 1999). 
Figura 4b. Frei José Marques e Silva, Te Deum (P-Mp R Mms 13/2, f. 4r.).

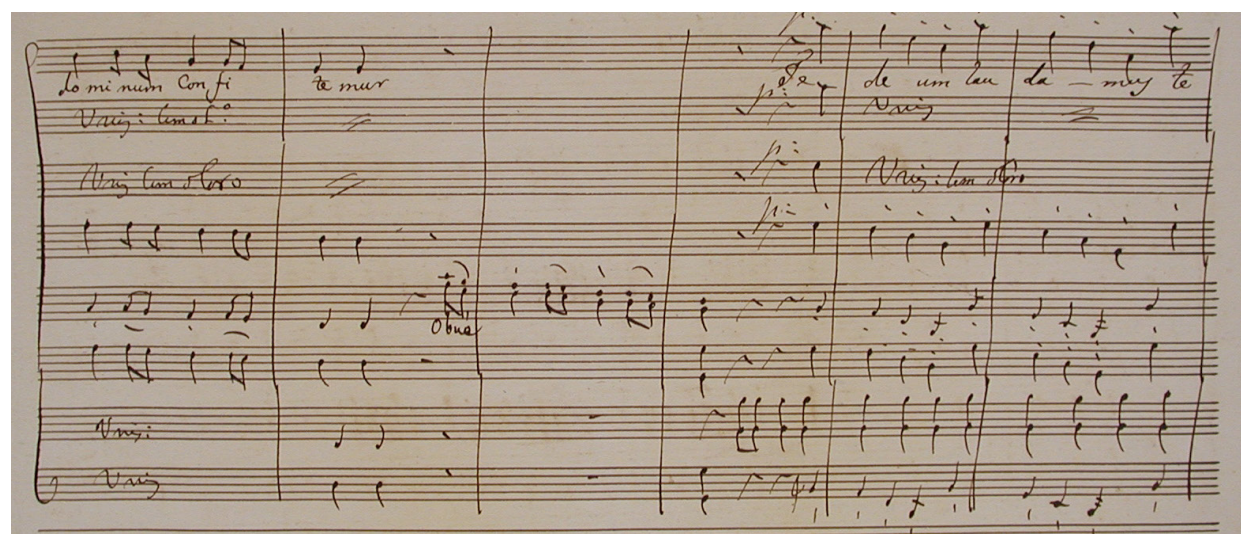

Embora normalmente essas mudanças sejam impossíveis sem a ajuda de assistentes, os pedais de anulação no órgão do Evangelho permitiam ao organista executá-las facilmente enquanto tocava. Considerando que os registos de cheio e de palhetas tinham sido previamente ligados, as alterações de registação seriam feitas conforme indicado na seguinte tabela:

Tabela 1. Utilização dos pedais anuladores no Te Deum de Frei José Marques e Silva (Órgão I, cc. 16-33).

\begin{tabular}{|c|c|c|c|}
\hline Compasso & Registação & Pedal esquerdo (cheios) & Pedal direito (palhetas) \\
\hline 16 & Flautado & $\leftarrow$ (inactivo) & $\mathrm{y}$ (todas as palhetas inactivas) \\
\hline 19 & Clarim & $\leftarrow$ (inactivo) & $\boldsymbol{K}$ (Trompa e Clarim activos) \\
\hline 21 & Flautado & $\leftarrow$ (inactivo) & $y$ (todas as palhetas inactivas) \\
\hline 25 & Clarim & $\leftarrow$ (inactivo) & $\boldsymbol{k}$ (Trompa e Clarim activos) \\
\hline 25 & Cheio & $\rightarrow$ (activo) & $\forall$ (todas as palhetas inactivas) \\
\hline 29 & Flautado & $\leftarrow$ (inactivo) & $\forall$ (todas as palhetas inactivas) \\
\hline 31 & Obué & $\leftarrow$ (inactivo) & $\lambda$ (Obué activo) \\
\hline 33 & Flautado & $\leftarrow$ (inactivo) & $\mathrm{y}$ (todas as palhetas inactivas) \\
\hline
\end{tabular}

A parte do Orgão $2^{\circ}$ (supostamente tocada no órgão da Epístola) é menos exigente em termos de registação, usando principalmente o pedal anulador dos cheios. Nos compassos 31 a 38 da referida secção inicial desta obra (Figura 5), as mudanças de registação do Órgão I (Flautado - Obué - Flautado - Cheio), facilmente realizáveis no órgão do Evangelho, seriam impossíveis de realizar no órgão da Epístola, que não dispõe de um anulador para os registos de palheta de ressoador curto (Fagote e Oboé). Pelo contrário, as mudanças exigidas ao Órgão II (Flautado - Clarim - Cheio) podem obter-se com facilidade no órgão 
da Epístola, através dos pedais anuladores dos cheios e das palhetas de ressoador longo (Trompa de batalha e Clarim).

Figura 5. Frei José Marques e Silva, Te Deum, cc. 31-38.

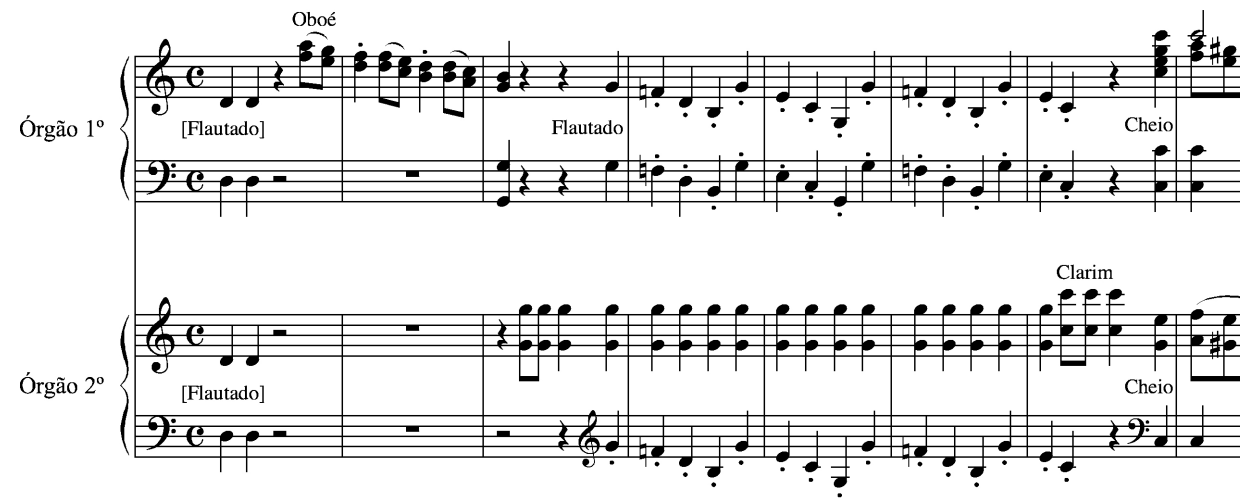

O facto de que a primeira obra executada nos órgãos reformados da Capela-Mor seja tão adaptada aos instrumentos parece ser mais do que uma mera coincidência. É, pois, admissível considerar a possibilidade de algum tipo de ligação entre o compositor e o organeiro.

Há outros elementos que parecem apoiar esta teoria. O órgão do Evangelho na Basílica de Mafra é um dos raros casos em que Machado e Cerveira instalou um dispositivo independente para anular as palhetas de ressoador curto. Este sistema é único porque um único pedal permite activar duas corrediças diferentes - uma para as palhetas de ressonador longo (Trompa de batalha da mão esquerda e Clarim da mão direita) e outro para as palhetas de ressonador curto (Fagote da mão esquerda e Oboé de 16' da mão direita). Este registo de palheta de ressonador curto de 16' é frequentemente chamado Rabecão por Marques e Silva, sendo um dos seus registos solísticos favoritos. Curiosamente, o único instrumento em Lisboa com possibilidade de anular independentemente as palhetas mais suaves (também neste caso $8^{\prime}$ à esquerda e 16' à direita) é o órgão da Capela da Bemposta, onde Frei José Marques e Silva era organista (Figura 6) ${ }^{13}$.

Após o Te Deum de 1812, Frei José Marques e Silva continuou a escrever para Mafra, e a estrutura das suas composições foi também reflectindo a progressão do trabalho de Cerveira nos órgãos da Basílica. O seu motete Veni Assur, escrito em

13. Este órgão pode ter sido sujeito a alterações e podem subsistir dúvidas sobre sua especificação original. No entanto, é claro que um registo de palheta (dividido em dois meios-registos) está colocado sobre uma corrediça deslizante de anulação na parte posterior do someiro principal. 
1814, usa três órgãos e seu Laudamus Te (sem data ${ }^{14}$ ) exige quatro. Finalmente, uma Missa escrita em 1825 para a festa de São Francisco faz uso de cinco órgãos. $\mathrm{O}$ modo como a escrita musical de Frei Marques e Silva recorre às idiossincrasias dos instrumentos de Cerveira torna altamente provável que o organista da Capela da Rainha e o construtor de órgãos do Reino se encontrassem. A análise de várias das suas obras sugere uma influência mútua: não apenas a música de Marques e Silva é claramente pensada em função dos órgãos de Cerveira, como também algumas características específicas dos instrumentos podem ter sido criadas por sugestão do compositor. As transformações na música de órgão portuguesa durante a fase final do Antigo Regime e o desenvolvimento de um tipo de instrumento gradualmente destacado da tradição hispânica parecem não ser apenas uma questão de causa e efeito (numa ou noutra direcção), mas o resultado de um esforço comum rumo a um universo mais orquestral e operático no campo da música sacra e da música de órgão.

Figura 6. Capela da Bemposta, órgão (António Xavier Machado e Cerveira, 1792).

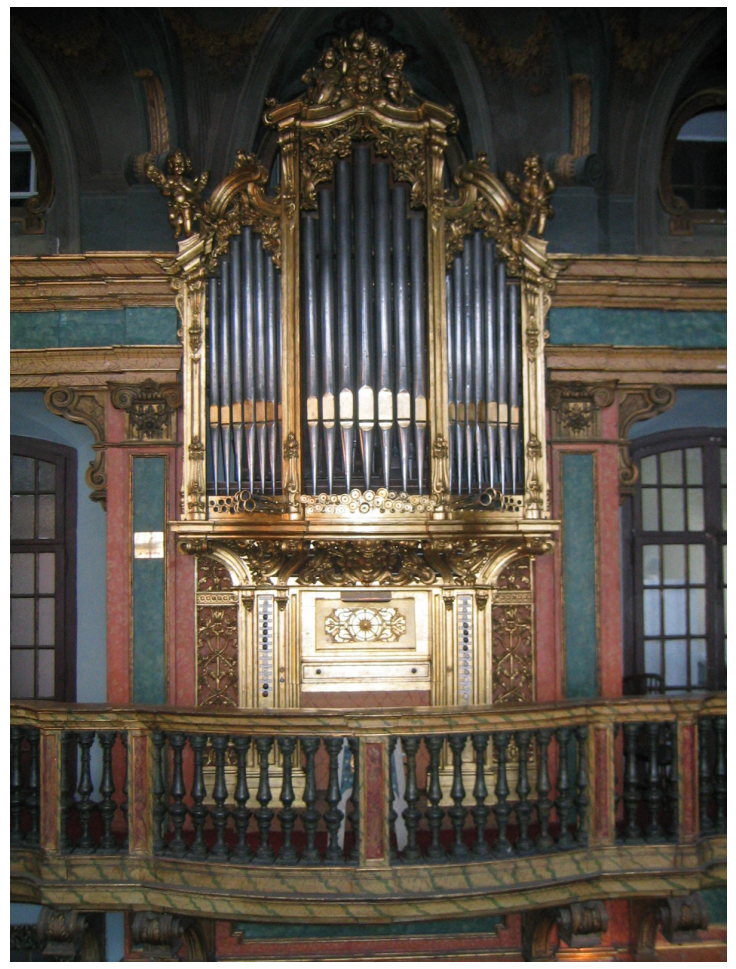

14. Embora sem data, o facto de esta obra ter sido cantada pelo castrato Francisco Maria Angelelli implica que tenha sido escrita antes de 1828, quando ele cantou pela última vez (Vieira, 1900, Vol. 1, p. 32). Por outro lado, o uso de quatro órgãos sugere uma data entre 1814, quando aparentemente só três estavam disponíveis, e 1825, quando cinco já estavam em condições de serem tocados. 


\section{Referências}

Baena, G. (1540). Arte nouamente inventada pera aprender a tanger. Lisboa, Portugal: German Galhard.

Brescia, M. A. (2013). L'école Echevarría en Galice et son rayonnement au Portugal (Tese de doutoramento em História da Música e Musicologia), Université Paris IV - Sorbonne / Universidade Nova de Lisboa.

Doderer, G. (2005). Beiträge zur Orgelbaugeschichte von Mafra (Portugal). In R. Behrens \& C. Grohmann (Eds.), Dulce melos organorum: Festschrift Alfred Reichling zum 70. Geburtstag (pp. 81-110). Mettlach, Alemanha: GdO - Gesellschaft der Orgelfreunde.

Pearson, K. (2012) Three Organ Quartets by António José Soares: A Study in Part Distribution for the Organs in the Basilica of Mafra, Portugal (Relatório de Projecto Artístico de Mestrado), Escola Superior de Música de Lisboa.

Vaz, J. (2015) The Six Organs in the Basilica of Mafra: History, Restoration and Repertoire. The Organ Yearbook, Vol. XLIV, 83-101.

Vaz, J. (2013) Dynamics and Orchestral Effects in late Eighteenth-Century Portuguese Organ Music: The Works of José Marques e Silva (1782-1837) and the Organs of António Xavier Machado e Cerveira (1756-1828). In J. Kitchen \& A. Wooley (Eds.), Interpreting Historical Keyboard Music: Sources, Contexts and Performance (p. 157-172). Farnham, Reino Unido: Ashgate.

Vaz, J. (2010) A obra para órgão de Fr. José Marques e Silva (1782-1837) e o fim da tradição organística portuguesa do Antigo Regime (Tese de doutoramento em Música e Musicologia), Universidade de Évora.

Vieira, E. (1900) Diccionario biographico de musicos portuguezes: historia e bibliographia da Musica em Portugal (2 vols.). Lisboa, Portugal: Lambertini. 